\title{
A Reliability-Centered Maintenance Study for an Individual Section-Forming Machine
}

\author{
Samuel Okwuobi ${ }^{1}$, Felix Ishola ${ }^{2, *}$, Oluseyi Ajayi ${ }^{2, *}$, Enesi Salawu ${ }^{2}$, Abraham Aworinde ${ }^{2}$, \\ Obafemi Olatunji ${ }^{3}$ and Stephen A. Akinlabi ${ }^{3}$ \\ 1 Department of Mechanical Engineering, University of Lagos, Lagos 101017, Nigeria; \\ samuelokuwobi@gmail.com \\ 2 Department of Mechanical Engineering, Covenant University, Ota 112233, Nigeria; \\ enesi.salawu@covenantuniversity.edu.ng (E.S.); abraham.aworinde@covenantuniversity.edu.ng (A.A.) \\ 3 Department of Mechanical Engineering, University of Johannesburg, Johannesburg 2006, South Africa; \\ tunjifemi@gmail.com (O.O.); stephenakinlabi@gmail.com (S.A.A.) \\ * Correspondence: felix.ishola@covenantuniversity.edu.ng (F.I.); \\ oluseyi.ajayi@covenantuniversity.edu.ng (O.A.); Tel.: +23-480-606-151-84 (F.I.)
}

Received: 7 September 2018; Accepted: 23 October 2018; Published: 26 October 2018

\begin{abstract}
This study investigated the breakdown trend in an automated production with an aim to recommend the application of reliability-centered maintenance (RCM) for improved productivity via a new preventive maintenance (PM) program. An individual section-forming machine (ISM) — a glass blowing machine for making glass bottles-was used as the case study for an automated production system. The machine parts and the working mechanisms were analysed with a special focus on methods of processes and procedures. This will enable the ISM maintenance department to run more effectively and achieve its essential goal of ensuring effective machine operation and reduction in machine downtime. In this work, information is provided on the steps and procedures to identify critical components of the ISM using failure modes and effect analysis (FMEA) as a tool to come up with an optimal and efficient maintenance program using the reliability data of the equipment's functional components. A relationship between the failure rate of the machine components and the maintenance costs was established such that using the recommended PM program demonstrates evidence of an improvement in the machine's availability, safety, and cost-effectiveness and will result in an increase in the company's profit margin.
\end{abstract}

Keywords: reliability centered maintenance (RCM); individual section-forming machine; failure analysis; risk analysis

\section{Introduction}

The high level of competition among industries and businesses has made the survival battle tremendously strong. All over the world, producers are striving to further reduce production time loss as production time has cost implications while customers are more concern about the safety and reliability of the products [1]. This quest also includes employees who desire a safe work environment [2]. In the time past, testing and analysis used to be methods to measure reliability, this is no longer obtainable. The focus is on anticipating the factors that lead to failure and ensure that such factors are prevented from occurring frequently using a robust design [3]. To reach this goal, the decrease in the cost of operation is set as a high priority [4]. The study of reliability and maintainability in any manufacturing outfit plays a crucial role in ensuring the smooth running of the production process because it ensures production continuity as well as product quality [5].

Maintenance has been referred to as a single largest controllable cost which can be used to improve productivity through attempts to improve different maintenance policies [6]. A decision-making tool 
that has been widely implemented is reliability-centered maintenance (RCM). RCM is a tool usually used to understudy the failure pattern of a system so as to be able to make decision on best strategy that can be deployed to ensure that a system achieves the desired level(s) of operational reliability, safety, and readiness and then environmental safety in the most economical manner [7]. RCM is also a systemic consideration for functions, failures, safety and cost-effectiveness of maintenance practices. It is a process that can point to what should be done to guarantee a machine availability of the machine, performing intended functions efficiently [8]. Over the 30 years of implementing RCM, it has been tested and confirmed to be an effective preventive maintenance (PM) optimization strategy; a method that has enjoyed increasing popularity in a wide range of different industrial setups [9]. PM's objective is usually to crunch the probability of having a non-scheduled maintenance, which typically comes at a high cost. Bolu (2013) established the relationship between the measurement of maintenance performance and productivity as the major determinants for maintenance costs by adopting the following equations:

$$
\text { Cost of Maintenance }=\frac{\text { Total Maintenance Cost }}{\text { Total Maintenance Hour }}
$$

and

$$
\text { Maintenance Cost Component }=\frac{\text { Total Maintenance Cost }}{\text { Production Output }}
$$

therefore

$$
\text { Cost Reduction Ratio }=\frac{\text { Routine Service Workload }}{\text { Cost of Maintenance Hour }}
$$

given

$$
\text { Routine Service Workload }=\frac{\text { Planned Maintenance Hour }}{\text { Total Maintenance Hour }}
$$

Implying that the overall objective of the maintenance function is to support the production department by keeping facilities in proper running condition at the lowest possible cost [10]. For many other machines, RCM has been a successful PM strategy, and this time, it is being tailored for use in an individual section-forming machine (ISM) to aid the design of a planned component replacement (PCR) schedule [11]. This research aims to examine the present maintenance culture of an ISM in a glass bottle molding industry and to establish an RCM plan on this machine. From this, the PM intervals that give the best performance values were identified for an optimum maintenance plan and reduction in service period and frequency.

\subsection{Brief Description of Individual Section-Forming Machine (ISM)}

The individual section-forming machine (ISM) is an automatic machine used in producing hollow glass containers having narrow or wide necks. The machine is designed to be extremely flexible, hence, it is very efficient for the production of a very large range of containers depending on the mold installed. A furnace is usually an integral compartment of an ISM. It heats to over $1400{ }^{\circ} \mathrm{C}$ to melt the glass. The molten glass passes through a forehearth to the feeder where it is cut into uniform gobs of glass, i.e, the liquid glass drops by a thermal shearing and distribution system as shown in Figure 1. An overview of an ISM in action was shown in Figure 2 with an insert of a formed bottle. 


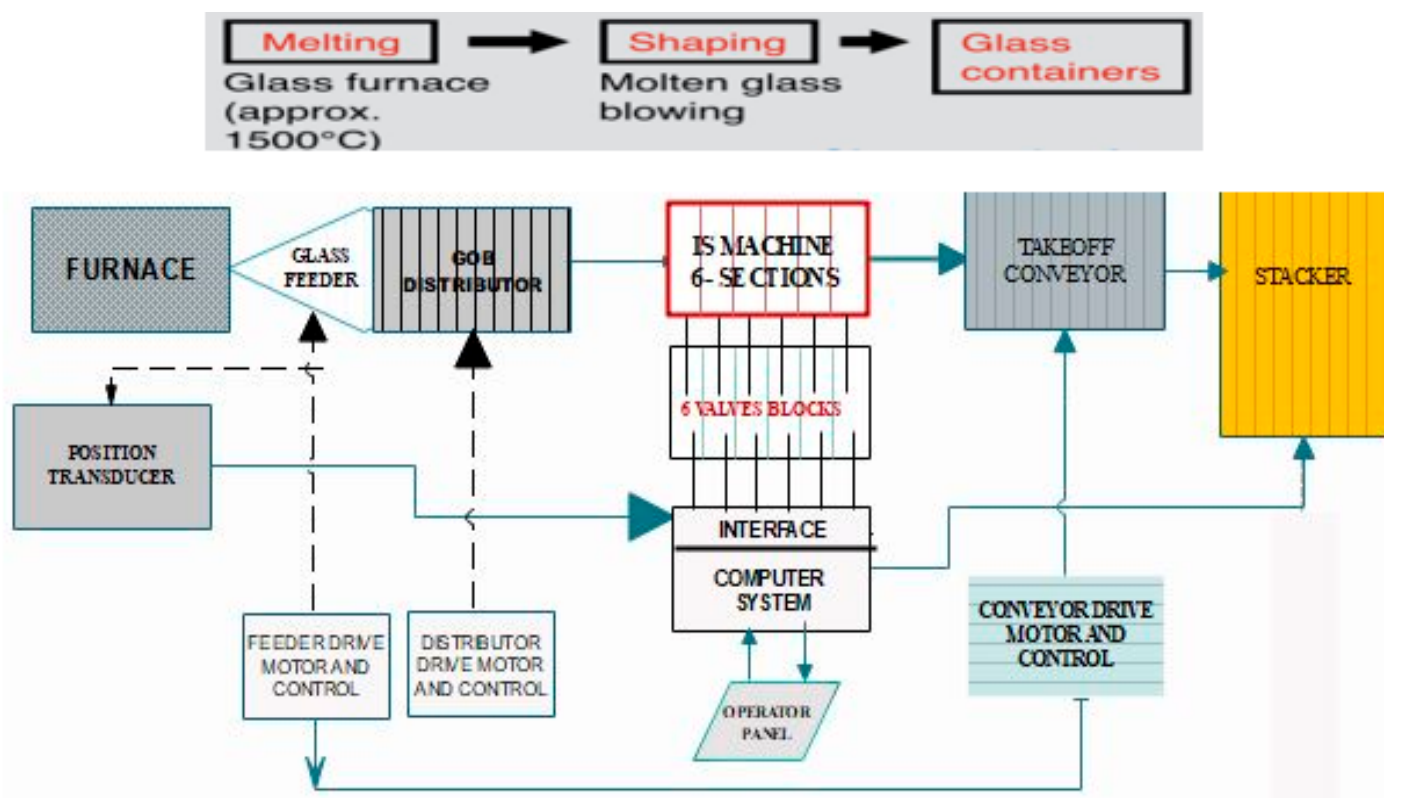

Figure 1. Process flow chart of a typical individual section-forming machine (ISM) [12].

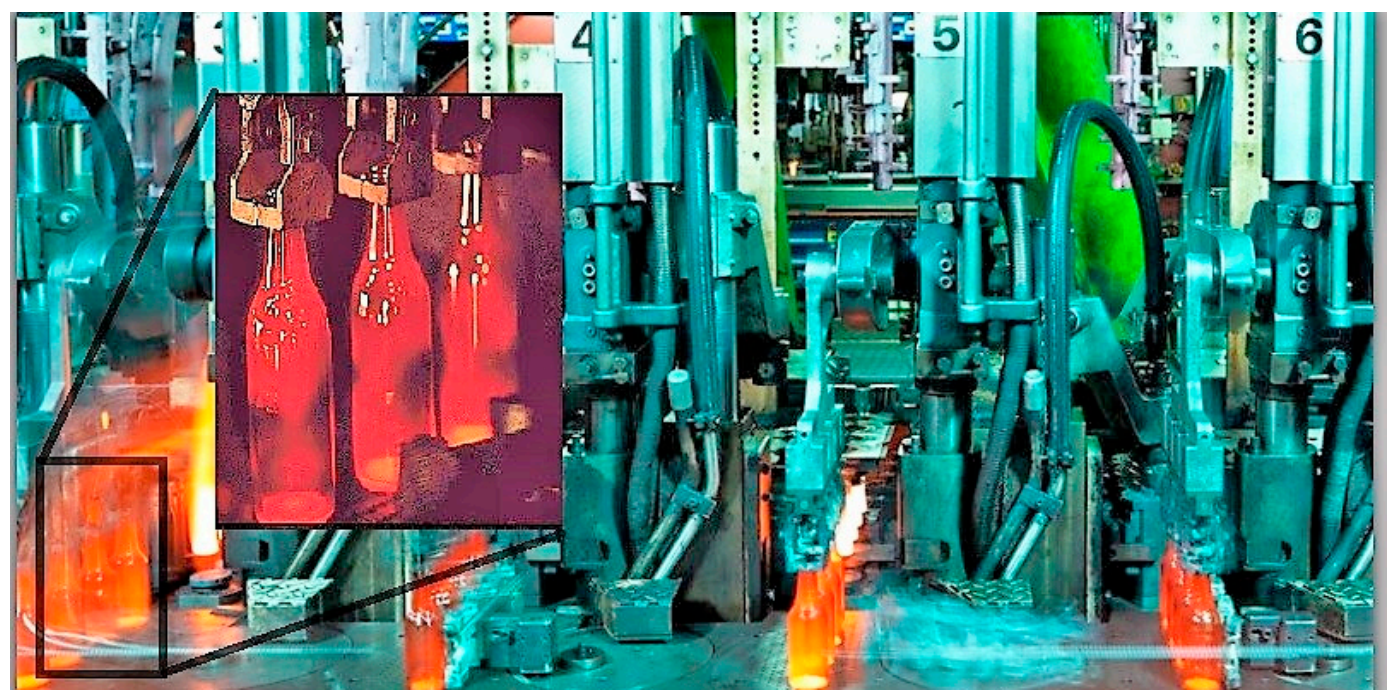

Figure 2. An overview of a typical ISM showing the operation of the plunger mechanism for take-out (Enlarged) [13].

After this, the gobs are sent to an ISM where the temperature reduces to below $1200{ }^{\circ} \mathrm{C}$, and the gobs are injected into the molds. The ISM molds are in two sets- "the blank" and "the blow" [14]. As described in Figure 3 below, the forming section is pneumatically driven, whereas, in the feeder mechanism, the gobs distributor and the pushers can be controlled by servo control or stepping motors. A solenoid-pneumatic valve block controlled by an electronic timer controls the mechanisms in all sections automatically [15]. 


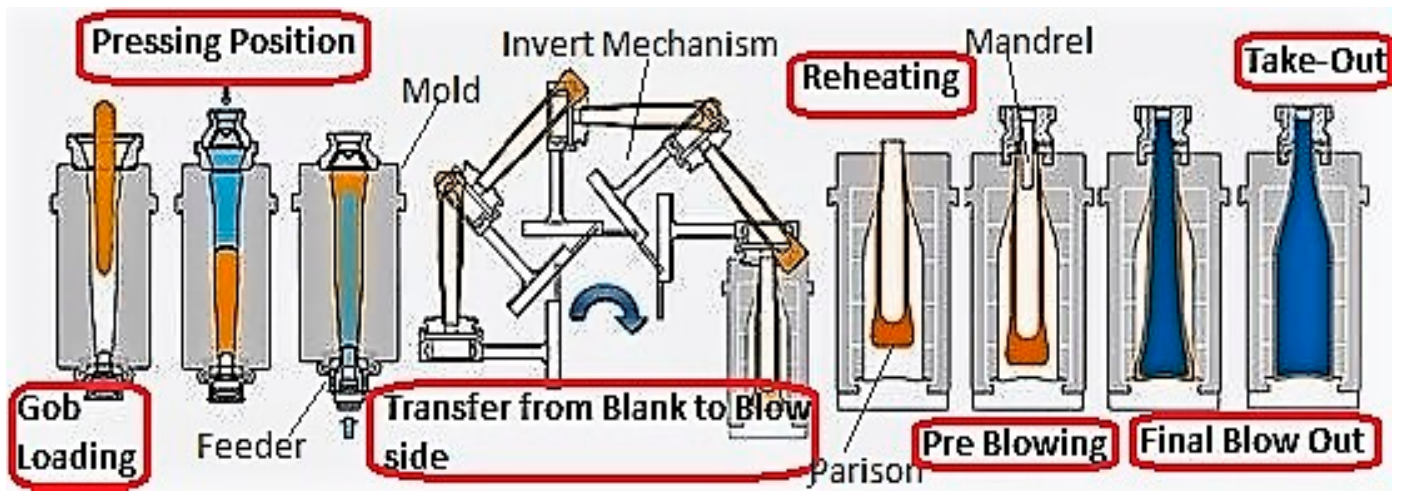

Figure 3. Diagram showing the main operations of an ISM [16].

Owing to the servo-controlled gob distributor, the number of machine sections to be used and the feeding sequence can be programmed to make the process completely automated [12]. The electronic pushers transfer the items from the cooling plate to the conveyor accurately, thus, improving item alignment on the conveyor. The time needed for job changes is, therefore, reduced as the pushers can be completely programmed [13]. As shown in Figure 1, there are six (6) independent sections which can be controlled and operated. Any form of operation or maintenance, such as the replacement of molds, can be performed without affecting other sections. As a matter of fact, different types and shapes of molds can be installed in different sections. The ISM is a critical success factor in glass bottle production, and it is more rewarding if kept at the optimum in-service condition [17].

\subsection{Overview and Review of RCM Related Work}

Like many other maintenance planning tools, RCM is used to preserve an item's functionality. RCM seeks to curtail the criticality of failure as all failures can never be eradicated [18]. The first priority of RCM is safety. In cases where safety is not jeopardised, the priority becomes maintenance justified by the ability to complete the mission of availability and reliability and then the final priority is based on cost-effectiveness [19]. These cumulating into making use of RCM for the design of the system; system's operation modes; the maintenance methods and practices; logistics, and costs data (analysis) to improve operating capability of such system(s). RCM has been found to be an integration of preventive maintenance (PM), Predictive testing and inspection (PT\&I), reactive maintenance (repair) and proactive maintenance to minimize maintenance cost and downtime and consequently increase the probability of function-ability of a machine over its expected lifespan; this is succinctly represented in Figure 4 below while Figure 5 highlighted the flowchart of RCM analysis [20].

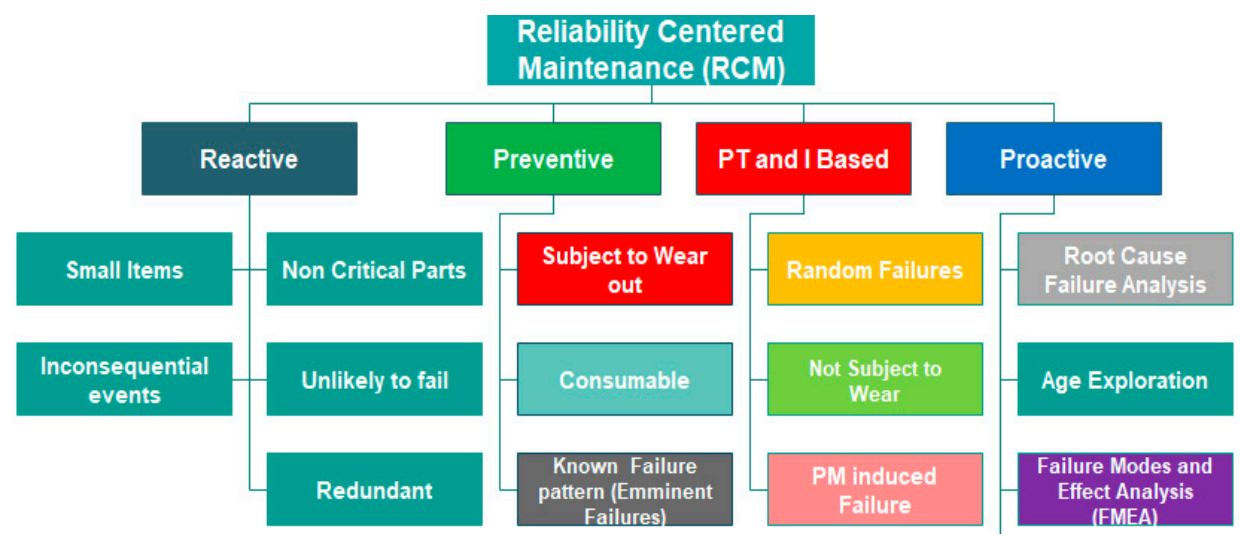

Figure 4. Components of a reliability-centered maintenance (RCM) program. 


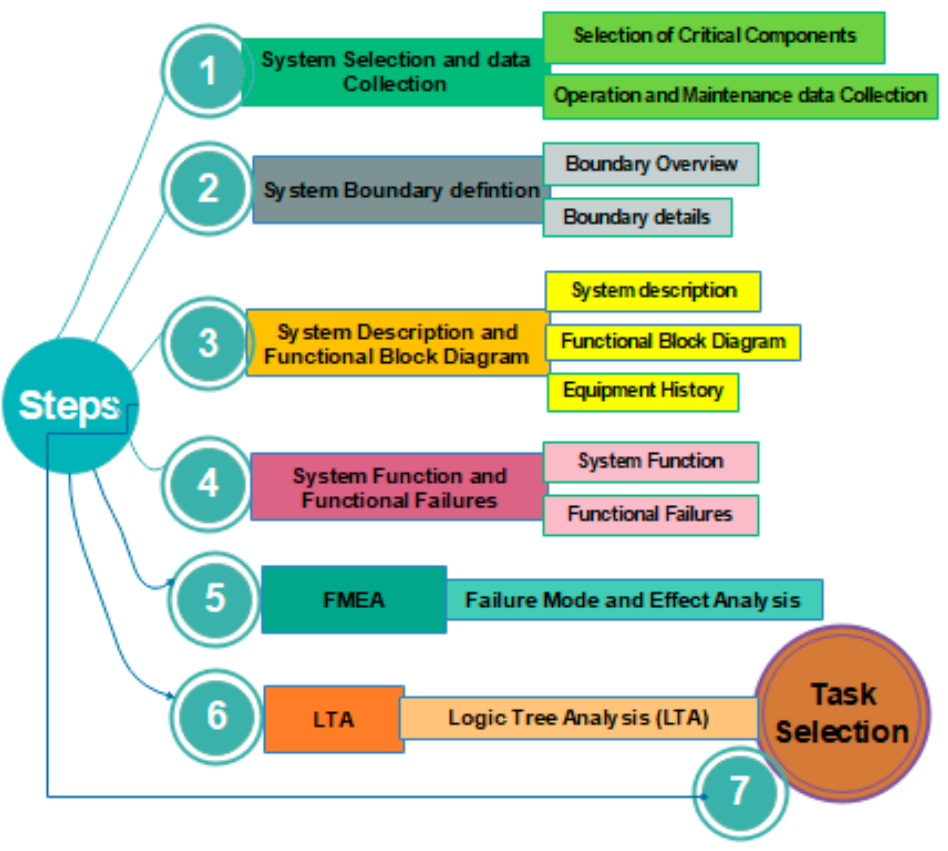

Figure 5. A flowchart for the RCM analysis [21].

RCM should be a continuous process that requires sustaining because it is known that any system's best maintenance can only sustain a system to its inherent reliability and availability level within the operating context [22]. The condition-monitoring system (CMS) is an integral component of RCM to increase productivity and reliability of machines as shown in Figure 6 below (Item 3). The conditions leading to failure mode must have been or be investigated using sensors like accelerometers, encoders, current/torque sensors, and pressure sensors as well as temperature sensors [23].

\begin{tabular}{|c|c|}
\hline 1. Functions & $\begin{array}{l}\text { - The desired performance standards of of the system, how well it } \\
\text { performs, and under what circumstances }\end{array}$ \\
\hline 2. Functional Failures & $\begin{array}{l}\text { - The various states that the system and equipment fail to meet } \\
\text { expectations; this includes both partial and total failures. }\end{array}$ \\
\hline 3. Failure Modes & $\begin{array}{l}\text { - Monitoring conditions causing a functional failure. A failure on similar } \\
\text { equipment can be projected to likely same trigger events in another. }\end{array}$ \\
\hline 4. Failure Effects & $\begin{array}{l}\text {-Description of what happens when each failure mode occurs, } \\
\text { detailed enough to correctly evaluate the consequences of each }\end{array}$ \\
\hline 5. Failure Consequences & $\begin{array}{l}\text { - The effect; for any deflection from expected function on the safety, } \\
\text { environmental, mission, or economics of the system }\end{array}$ \\
\hline 6. Maintenance Policies & $\begin{array}{l}\text {-Applicable, effective and economical plans, to predict, prevent or } \\
\text { mitigate failures. }\end{array}$ \\
\hline 7. Other Logic & $\begin{array}{l}\text {-Including, but not limited to, engineering redesigns, run-to- } \\
\text { failure, modification to operating procedures and machine feature } \\
\text { reconditioning. }\end{array}$ \\
\hline
\end{tabular}

Figure 6. An overview of the items of the RCM process in sequence [24].

From the past researches, it is evident that RCM has been used as a tool to sort out failure problems ranging from the field of medicine to military to building-related technologies to automotive to aviation and, of course, industrial and production to mention few. Wang et al. (2000) [25] carried out an RCM analysis of process equipment using heat exchangers as a case study. Results indicated that RCM could assist in identifying the functional failures, causes of failures, and risk ranking which are linked 
to corrosion rates and the remaining life of the heat exchangers. Afefy (2010) [26] investigated the application of RCM methodology to the development of a maintenance plan for a steam-process plant. The proposed RCM spiced PM planning indicated that the system will enjoy about a $25.8 \%$ decrease in total labour cost, an $80 \%$ reduction in total downtime cost, and also about a $22.17 \%$ decrease in the annual spare parts cost for the proposed RCM-PM planning application. Ramli \& Arffin (2012) [27] also carried out research on RCM in the schedule improvement of the automotive industry. The number of checklists in the body shop was reduced, and this resulted in a significant reduction in the operator's workload and prevented fraud by maintenance personnel. It was confirmed that the implementation of RCM provided a high level of success and the same methodology could be applied to equipment in other shops [25-27].

Tarar (2014) [28] carried out a study on RCM for rotating equipment through predictive maintenance. This paper evaluated the effectiveness of the existing maintenance strategy with optimization proposals. It showed the RCM process for a case study of paint booth fans process. The paper revealed that successful RCM implementation in any given industry can ensure improved performance to gain an edge over competitors in the global market. Recently, Emovon et al. (2018) [29] carried out a review on the development of more effective RCM tools for maintenance practices in plant systems for increased safety and efficiency. Some authors have pointed out the drawbacks of the risk priority number (RPN) as they established that RPN is not able to depict exactly the severity of some failure modes especially when certain factors such as economic cost and environmental impact are involved in the risk analysis [30]. Consequently, some other authors integrated the weighted aggregated product assessment (WASPAS) into RCM as an alternative for prioritizing the use of the RPN [31]. The technique was said to improve the effectiveness of RCM as well as in the selection of an optimal maintenance strategy for some industrial applications [32]. Further to the previous researches, this research seeks to implement the RCM for an individual section-forming machine (ISM) which is used in a glass bottle production company. RPN is considered the best option for the nature of the data collected for this study as some of the alternatives are found to require a maintenance data collection pattern a little different from the conventional $[28,29,33]$.

\section{Materials and Methods}

\subsection{Components of Individual Section-Forming Machine (ISM)}

The individual section-forming machine usually comprises even-numbered sections. Besides operating as a single machine, two machines can be connected in line. Furthermore, the number of working sections can be changed and the kiln delivery capacity is of fundamental importance. To produce special items, auxiliary mechanisms and equipment are available to be used on the machine, such as the single, double, triple, quadruple gob, blow-blow, press-blow, narrow neck press-blow processes, vacuum mold, and blow mold support, as well as special equipment for the different production processes [12]. A more flexible production system is at present available owing to the servo-feeder, gob servo-distributor, servo-pusher, and the electric shaft system for flexible lines.

\subsection{Mechanism Selection Process}

The criteria for the selection of the components are as follows:

- The frequency of downtime/failure of a component

- Type of components as to whether it is a mechanism or a variable

- Criticality of component failure

- Availability of technical description and maintenance guidelines for the component

- Information gathered from a questionnaire on the reliability of components. 


\subsection{Questionnaire Design for Individual Section-Forming Machine Maintenance Staff}

In the course of the research, questionnaires were administered to all maintenance staff, key production crews, and forehearth staff of Beta Glass Plc. The company is located at Ogun State in Nigeria. They are specialized in the production of glass containers particularly bottles. The aim of the questionnaires was to investigate the machine functionality, capability, and reliability and also the distribution of roles in the maintenance department. The information used spans across 15 quarters between the year 2010 and 2014 (i.e., each report is compiled for three months) with each quarter labelled 1st to 15th.

\subsection{Failure Risk Analysis}

For each of the identified components of the ISM, the risk analysis for experiencing any form of failure was conducted based on the available data, using failure modes and effect analysis (FMEA), and also a downtime analysis of the components across the period was considered [34].

Step 1: Review all processes involved in getting the product.

Step 2: Highlight all possible failure modes.

Step 3: Exhaust all the possible effects of each failure mode.

Step 4: Assign ranking for the severity of each effect.

Step 5: Assign ranking for the probability of occurrence of each failure mode.

Step 6: Assign ranking for ease of detection of each failure mode.

Step 7: Compute the risk priority number (RPN) for each of the failure modes.

The severity ranking $(\mathrm{S})$, the occurrence ranking $(\mathrm{O})$, and the detection ranking $(\mathrm{D})$ used for the analysis are as shown in Tables 1-3.

\section{Risk Priority Number $=$ Severity $\times$ Occurrence $\times$ Detection}

$$
R P N=S^{*} O^{*} D
$$

The mechanism input sources for FMEA is as follows:

- Questionnaires completed by maintenance staff.

- Downtime data showing details of failure which occurred.

- Working drawings of components.

- Maintenance instructions as provided by manufacturers.

- Failure modes and effects analysis of standard mechanical components.

- On field assembly and disassembly during repairs and diagnostics of fault.

Table 1. Ranking for the severity of each failure (S).

\begin{tabular}{cl}
\hline Definition & \multicolumn{1}{c}{ Rating } \\
\hline No Effect & 1. None \\
Within specified limits & 2. Very Minor \\
Downtime $0-10$ min no defects & 3. Minor \\
Downtime 10-30 min no defects & 4. Very Low \\
Downtime $30-60$ min, $1 \mathrm{~h}$ of defects & 5. Low \\
Downtime and defects 1-2 h & 6. Moderate \\
Downtime $>4 \mathrm{~h}$, defects $2-4 \mathrm{~h}$. & 7. High \\
Downtime $>8$ h., defects $>4 \mathrm{~h}$. & 8. Very High \\
Affects personnel & 9. Hazardous with warning \\
Safety / regulations & 10. Hazardous w/o warning \\
\hline
\end{tabular}


Table 2. Occurrence ratings of failures/cycles (O).

\begin{tabular}{cl}
\hline \multicolumn{1}{c}{ Definition } & \multicolumn{1}{c}{ Rating } \\
\hline$<1 / 900,000, \mathrm{R}(\mathrm{t})=98 \%, \mathrm{MTBF}=50 \times$ & 1. Very low \\
$1 / 900,000, \mathrm{R}(\mathrm{t})=95 \% \mathrm{MTBF}=20 \times$ & 2. Low \\
$1 / 540,000, \mathrm{R}(\mathrm{t})=90 \% \mathrm{MTBF}=10 \times$ & 3. Low \\
$1 / 360,000, \mathrm{R}(\mathrm{t})=85 \% \mathrm{MTBF}=6 \times$ & 4. Moderate \\
$1 / 270,000, \mathrm{R}(\mathrm{t})=78 \% \mathrm{MTBF}=4 \times$ & 5. Moderate \\
$1 / 180,000, \mathrm{R}(\mathrm{t})=61 \% \mathrm{MTBF}=2 \times$ & 6. Moderate \\
$1 / 90,000, \mathrm{R}(\mathrm{t})=37 \% \mathrm{MTBF}=\mathrm{Spec}$ & 7. High \\
$1 / 36,000, \mathrm{R}(\mathrm{t})=19 \% \mathrm{MTBF}=0.6 \times$ & 8. High \\
$1 / 900, \mathrm{R}(\mathrm{t})=5 \% \mathrm{MTBF}=0.3 \times$ & 9. Very High \\
$>1 / 90, \mathrm{R}(\mathrm{t})<1 \% \mathrm{MTBF}=0.1 \times$ & 10. Very High \\
\hline
\end{tabular}

Table 3. Failure detection ranking (D).

\begin{tabular}{ll}
\hline Definition & Rating \\
\hline Almost Certain & 1. \\
Very High & 2. \\
High & 3. \\
Moderate-High & 4. \\
Moderate & 5. \\
Low & 6. \\
Very Low & 7. \\
Fairly Remote & 8. \\
Remote & 9. \\
Very Remote & 10. \\
\hline
\end{tabular}

\subsection{Downtime Analysis}

The downtime and the effective downtime for each quarter were collated for the following three (3) selected critical mechanisms using the data collected from the maintenance department of the company. The effective downtime for each mechanism in each quarter was collated with the financial loss as a result of the listed downtime. The cost of downtime is estimated by taking note of the production speed for each product as shown in Table 4 below.

$$
V_{b}=V \times n
$$

where $n=$ number of gob; $V_{b}=$ bottle speed; $V=$ average production speed price.

Table 4. Cost analysis of downtime.

\begin{tabular}{|c|c|c|c|c|}
\hline $\begin{array}{c}\text { Product } \\
\text { (Bottle Types) }\end{array}$ & $\begin{array}{l}\text { Machine Speed } \\
(\text { (bpm) }\end{array}$ & $\begin{array}{c}\text { Unit } \\
\text { Price }(\$)\end{array}$ & $\begin{array}{l}\text { Bottle Speed } \\
\quad(\mathrm{bpm})\end{array}$ & $\begin{array}{l}\text { Production Speed Price } \\
\qquad(\$ / \mathrm{m})\end{array}$ \\
\hline $\mathrm{A}$ & 53 & 0.13 & 106 & 13.60 \\
\hline B & 89 & 0.08 & 178 & 14.14 \\
\hline C & 86 & 0.10 & 172 & 17.34 \\
\hline $\mathrm{D}$ & 63 & 0.13 & 126 & 16.73 \\
\hline $\mathrm{E}$ & 110 & 0.12 & 220 & 26.82 \\
\hline $\mathrm{F}$ & 130 & 0.12 & 260 & 31.70 \\
\hline G & 80 & 0.11 & 160 & 17.42 \\
\hline $\mathrm{H}$ & 126 & 0.11 & 252 & 27.44 \\
\hline I & 98 & 0.07 & 196 & 14.18 \\
\hline $\mathrm{J}$ & 112 & 0.05 & 224 & 11.69 \\
\hline $\mathrm{K}$ & 92 & 0.07 & 184 & 13.31 \\
\hline $\mathrm{L}$ & 43 & 0.12 & 86 & 10.50 \\
\hline M & 76 & 0.10 & 152 & 15.93 \\
\hline $\mathrm{N}$ & 122 & 0.03 & 244 & 8.26 \\
\hline
\end{tabular}


There were two gob mates in the plant, hence, the machine produces two bottles per unit delivery time. During the analysis, all electrical and non-direct control related issues were not considered.

\section{Results and Discussion}

Causes of failure were ranked, and then FMEAs were developed as well as the downtime analysis for the following selected critical components:

- $\quad$ Pusher cylinder

The function of the pusher mechanism is to transfer fully formed wares (glass bottles) from the pusher dead plate on to the machine conveyor where they are transferred for further processing.

- $\quad$ Plunger mechanism

The plunger mechanism is a very important mechanism on the individual section-forming machine performing the multiple and critical functions of forming the finish of the (mouth/tip) of the bottle and the initial shape of the bottle (parison) both on the blank side of the machine. When this is done, the parison is transferred to the final side by the neck ring mechanism for further processing.

- Ware transfer mechanism

The main function of the ware transfer is to transport fully formed bottles from the conveyor of the machine to the cross conveyor of the annealing Lehr.

\subsection{FMEA for the Pusher Cylinder}

Table 5 below assigned numbers (1-17) and Table 6, i.e., computation of failure modes and effect analysis (FMEA) for pusher cylinder had the following causes ranked by RPN.

Table 5. Causes of failure ranked 1 to 17 in a decreasing order of criticality for pusher cylinder.

\begin{tabular}{cc}
\hline S/N & Failure \\
\hline 1 & Air drawn past rod seals during actuation with a RPN of 75 \\
2 & Bad control with a RPN of 6 \\
3 & Excessive loading with a RPN of 42 \\
4 & Excessive side loading with a RPN of 120 \\
5 & Excessive temperature with a RPN of 120 \\
6 & Fracture, material faults with a RPN of 36 \\
7 & High temperatures wear out with an RPN of 8 \\
8 & Lubrication, wear out with a RPN of 284 \\
9 & Manufacturing error with a RPN of 126 \\
10 & Onappropriate tightening, excessive temperature with a RPN 90 \\
11 & Oring failure with a RPN of 80 \\
12 & Over tightening of 180 \\
13 & Seal leakage, piston cylinder ear with a RPN of 48 \\
14 & Side loading and piston wear, contaminants past rod seal with a RPN of 75 \\
16 & Stiction, binding with a RPN of 24 \\
17 & Vibration with a RPN of 180 \\
\hline
\end{tabular}


Table 6. Computation of failure modes and effect analysis (FMEA) for pusher cylinder.

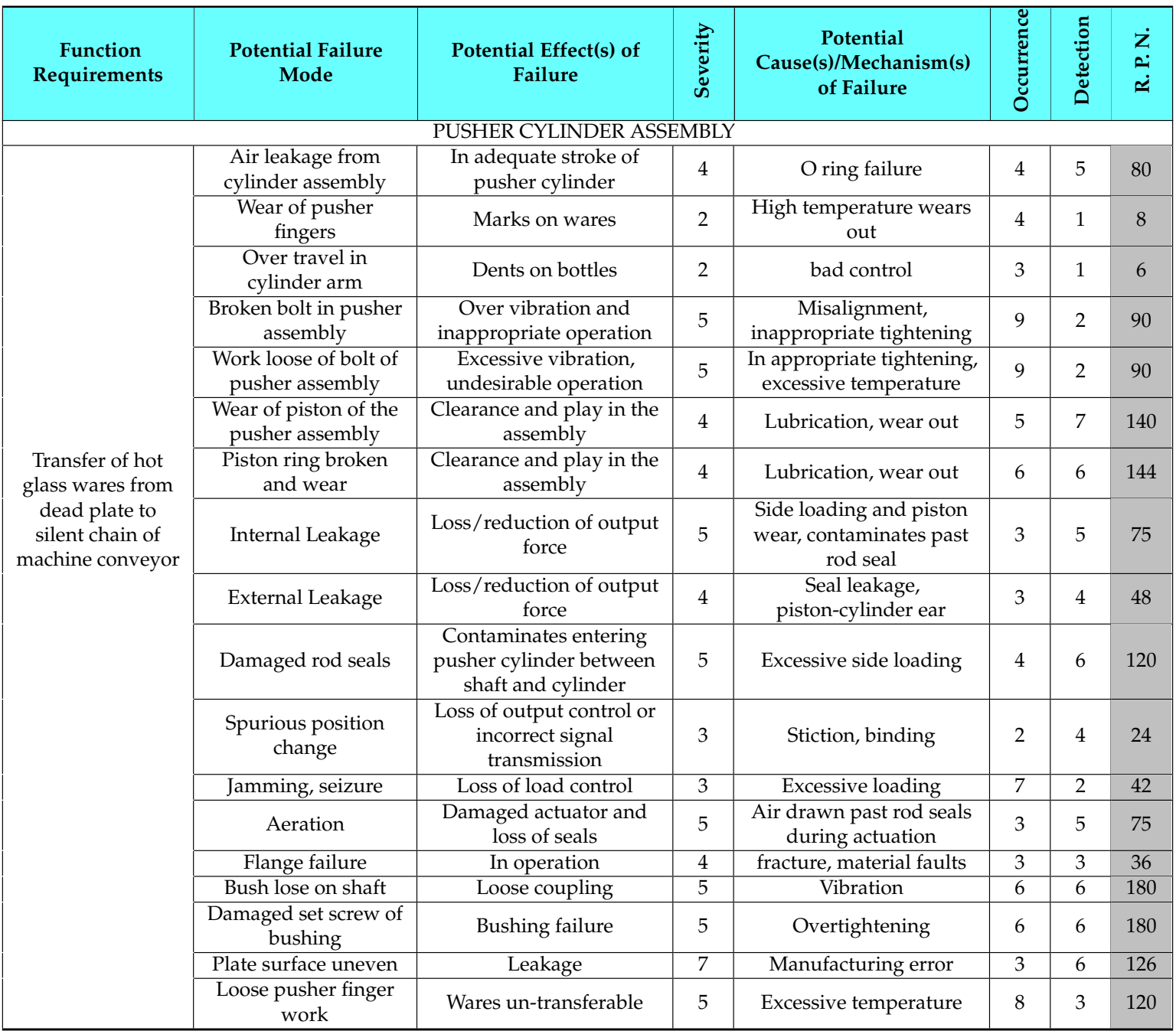

\subsubsection{Discussion of Results for Pusher Cylinder}

According to Figure 7, the highest RPN of 284 was due to Cause 9 which was worn due to lack of or insufficient lubrication (from Table 5) with a potential failure mode of a broken piston ring which will produce a primary effect of an internal leakage and the inappropriate movement of the pusher cylinder arm. The conducted RCM analysis also shows that inappropriate tightening (either too tight or too loose) of bolted parts accounts for the majority of the failures in the pusher cylinder. Excessive vibration as indicated in Cause 17 in Table 5 has the effect of bringing about work loosening of the assembled bolted joint or leading to Cause 13, i.e., overtightening of the part, thus, having the effect of inappropriate operation and also external leakages. A lesser RPN was observed for causes such as bad control and wear of pusher fingers due to high temperature and a hash working environment, because these failures have very low occurrence rates and were very detectable in cases in which they occurred. Figure 8 shows loss due to downtime of pusher cylinder across investigated periods, 14th quarter recorded highest monetary loss. 


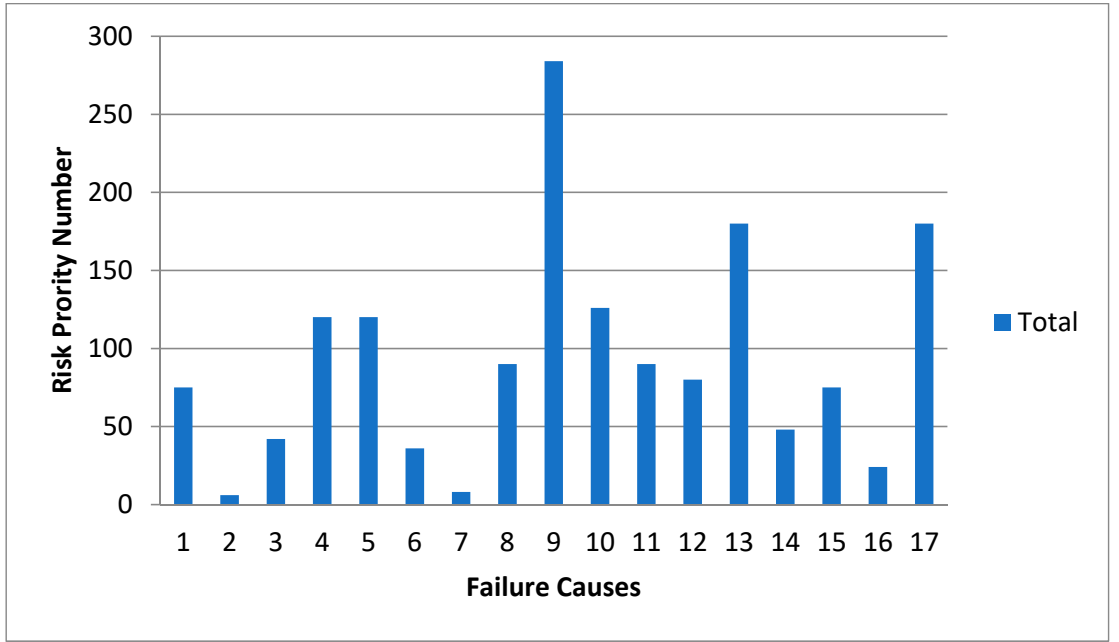

Figure 7. Distribution of failure causes to risk priority number (RPN) for pusher mechanism.

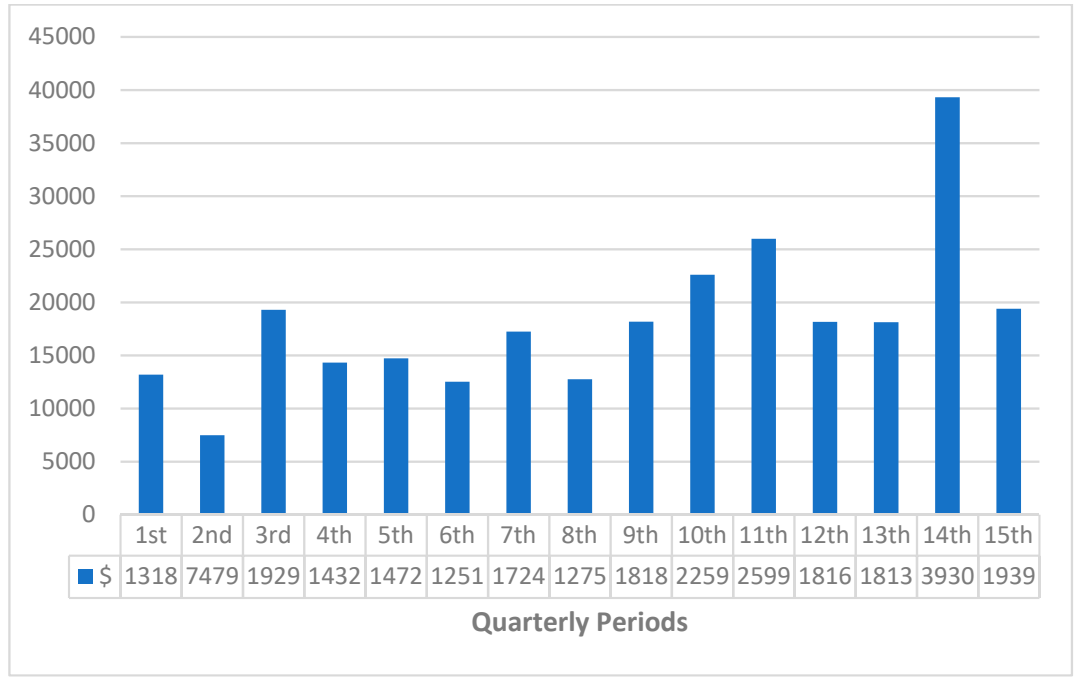

Figure 8. Loss due to downtime of pusher cylinder across investigated periods.

\subsubsection{Downtime and Cost Analysis}

The 14th period's data exhibits a conspicuous rise in downtime which was indicated with a loss of $\$ 39,308.97$ while the time lowest is of the second quarterly period which means that the pusher cylinder was mostly functional through the three months of the second period.

\subsection{FMEA for Plunger Mechanism}

\subsubsection{Discussion of Results for Plunger Mechanism}

Table 7 displays the computation of FMEA for the plunger mechanism while Figure 9 shows the distribution of the assigned numbers (1-11) had the following causes ranked by risk. It is observed that the highest RPN of 225 was due to Cause 7 which is the presence of carbon residue in upper cylinder. This leads to the potential failure mode of the plunger as it becomes stuck during operation due to the absence of clearance. In addition, it can be seen that wear of the upper cylinder due to a failure mode of air leakage in piston assembly had an RPN of 196. This is followed by a mismanagement of excessive working pressure which makes the plunger supply hose connector pull off with an RPN of 192 . A generally high RPN is observed for all failure causes of the plunder mechanism. This demonstrates the severity of the occurrence of such causes. Gasket flat had the lowest RPN of 84 due to failure 
modes of air leakage in inner mould during parison. This is because $\mathrm{p}$ ressure losses due to leakage can be compensated for by increasing the pressure. Even in cases of incomplete parison blowing, the effect is self-corrected during the final blowing process. Figure 10 Shows the distribution of failure causes to RPN for plunger mechanism.

Table 7. Computation of FMEA for the plunger mechanism.

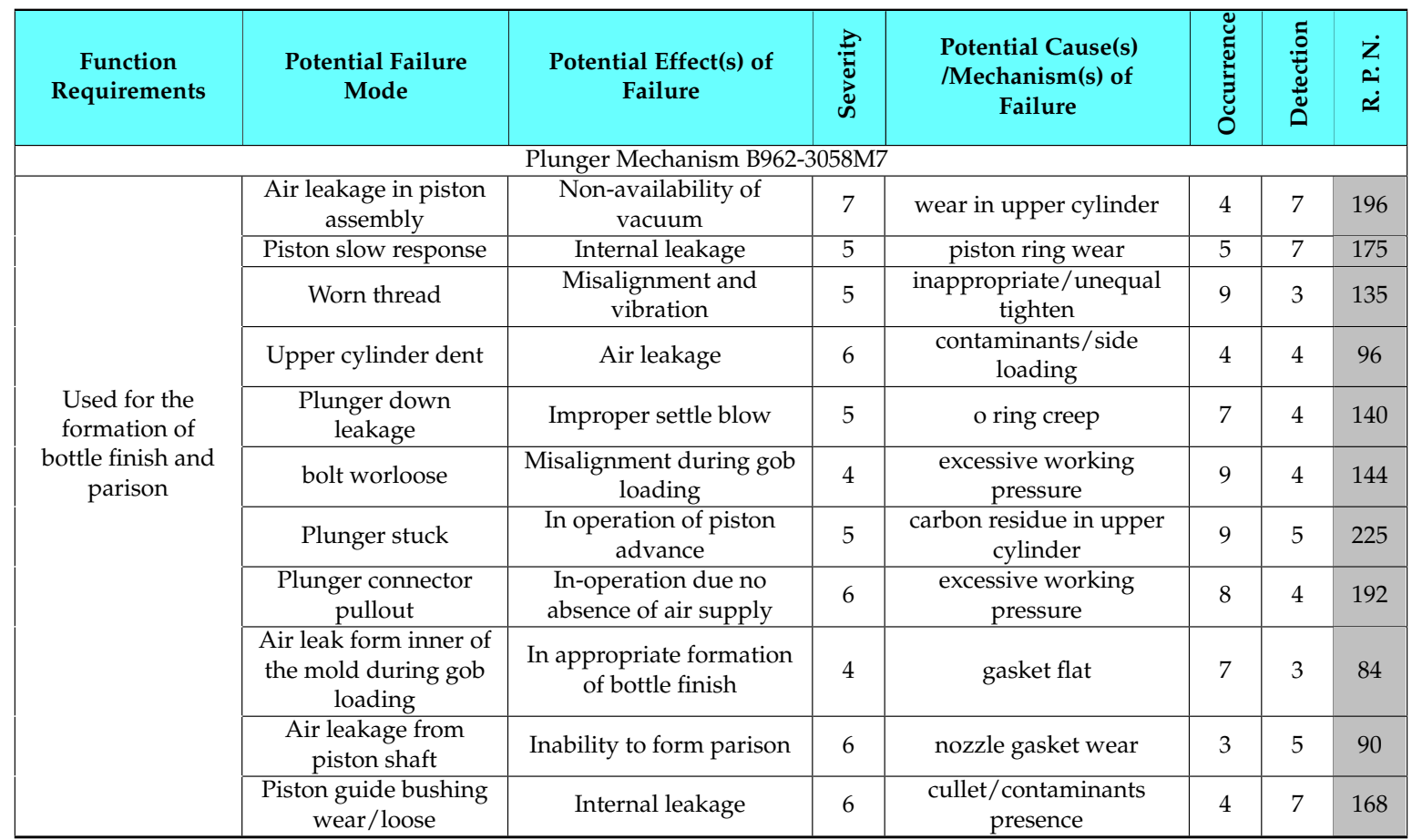

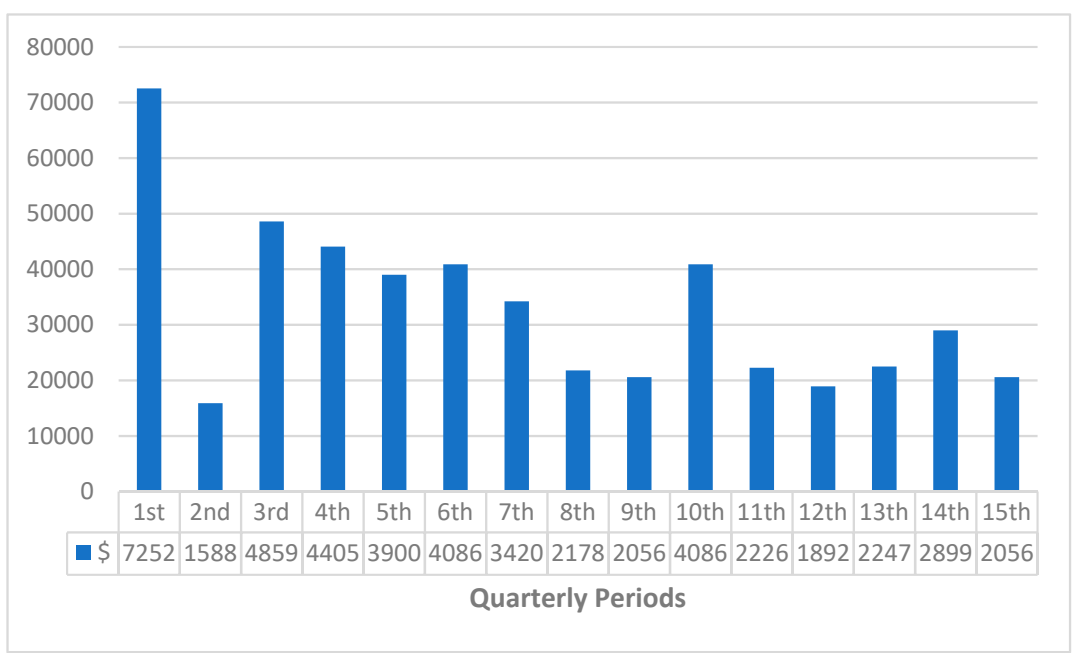

Figure 9. Loss in the cost of product not produced across quarterly periods for plunger mechanisms. 


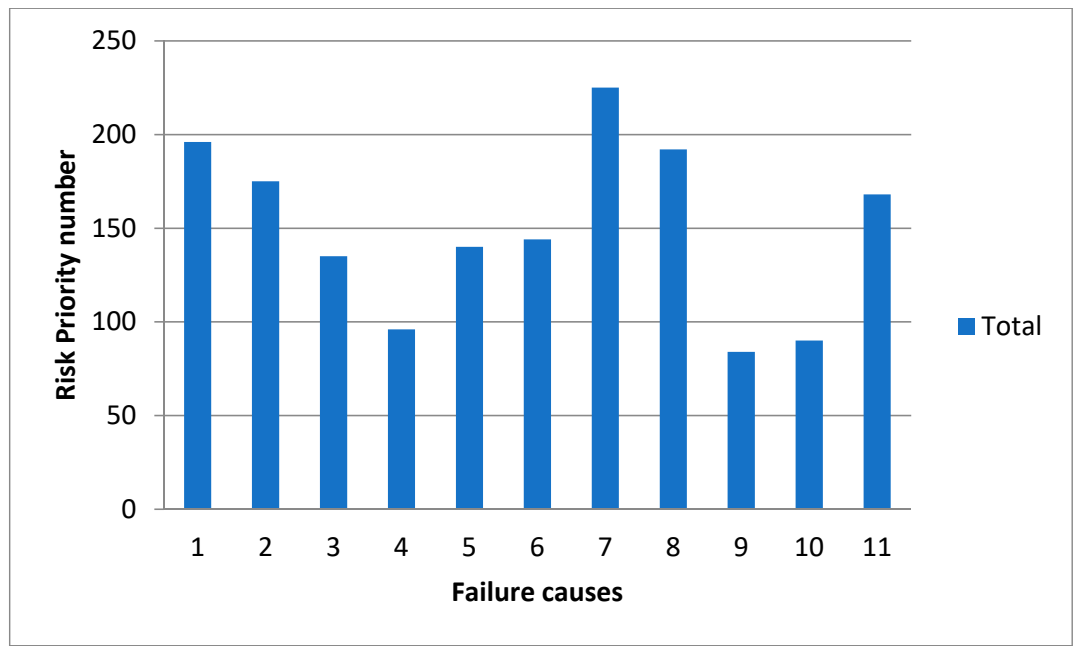

Figure 10. Distribution of failure causes to RPN for plunger mechanism.

\subsubsection{Downtime/Cost Analysis}

From the production records it was observed that the cost due to downtime was at the lowest in the 2nd quarter of the study period. However, the highest downtime cost loss was experienced in the 1 st quarter of the observation period with a $\$ 72,521.81$ loss in cost of products not produced as a result of the breakdown of the plunger mechanism.

\subsection{Discussion of Results for Ware Transfer}

From the distribution in Figure 11, assigned numbers (1-13) had the following causes ranked by RPN.

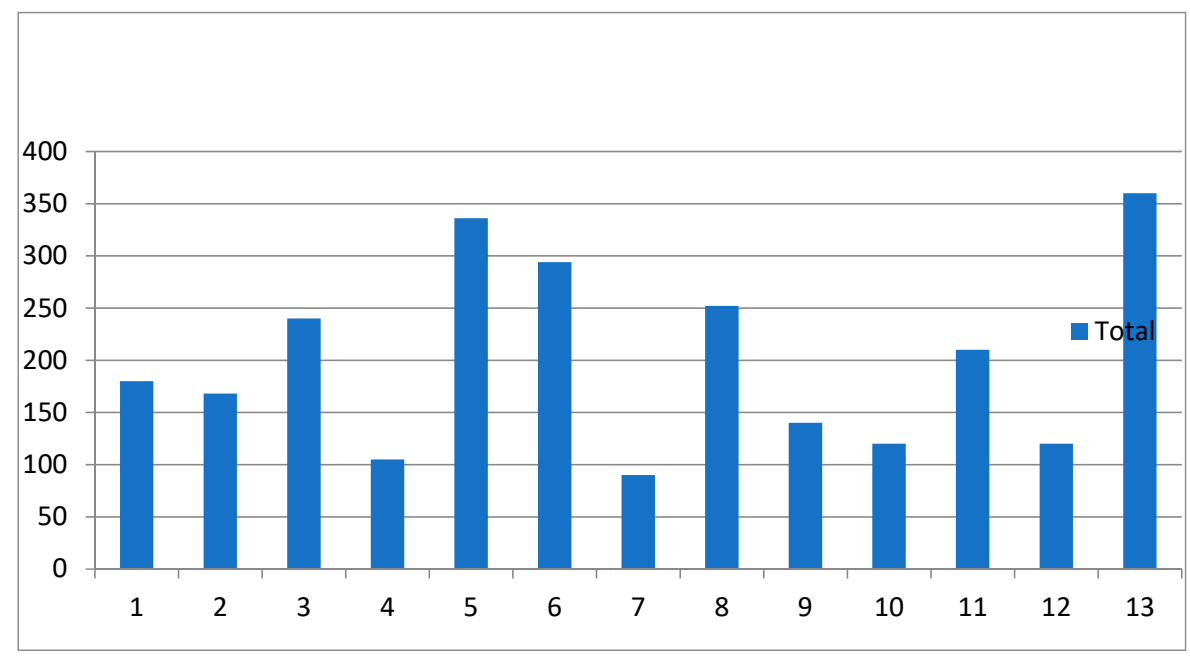

Figure 11. Distribution of failure causes to RPN for ware transfer mechanism.

The RCM analysis shows that the highest RPN of 360 was due to Cause 13 which is excessive heat and contamination. This has the potential failure mode of worn out of ware transfer fingers. Another high-temperature related failure which has a high probability of occurring with an RPN of 336 is identified with Cause 5 which is high temperature due to lack of lubricant in the ware transfer Mechanism. The failure mode associated with this defect is the clogging of the main bearing of the arms and linkages. Another high risk of the mechanism's failure was predicted to be the presence of contaminants in the lubricant of the bevel gear lubrication sump. This has a failure mode of abrasive wear of the bevel gears used in the transmission of motion for the shaft with the calculated RPN of 294 . 
A low RPN was observed in the case of detachment of bevel gear off on the shaft due to shear on the key. This is because the chances of this happening are rare and the failure mode is very easy to detect right from the early phase of installation and during maintenance activity. Another low-risk priority of 105 is linked with hooking of the cullet butt, this has a relatively high rate of occurrence rating of 7 , but it is also very easy to detect as well as quite easy to correct, hence, a low severity rating number.

\section{Downtime/Cost Analysis}

Considering the broad spectrum of all the quarters in Figure 12, there exists a minimal production downtime loss due to ware transfer failure. The exceptions are an extreme loss of over $\$ 82,000$ in the 10 th quarter and a relatively similar loss of $\$ 62,293.28$ in the quarter before. After which a relatively decreasing trend is shown in the loss associated with downtime from the 11th quarter of the observation period until the 15 th.

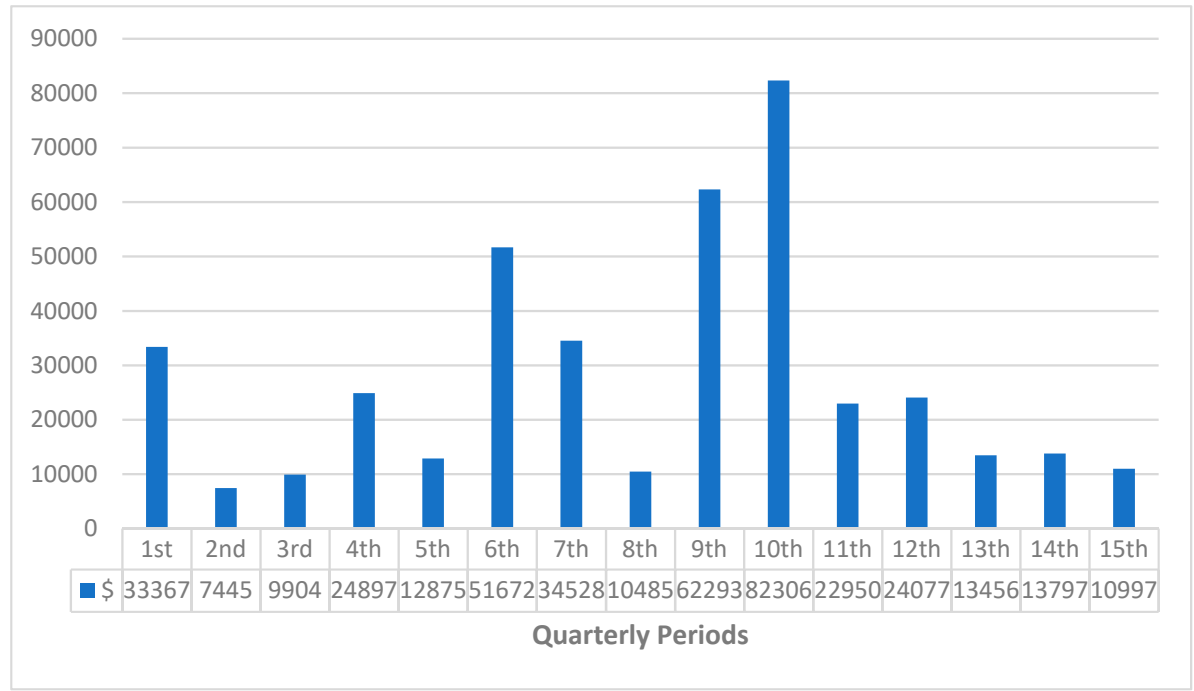

Figure 12. Loss in the cost of product not produced across the observed quarterly periods for ware transfer mechanism.

\section{Conclusions and Recommendation}

\subsection{Suggestion for the Improved Reliability of the Pusher Assembly}

Implementation of the selective run to failure, preventive maintenance, and precision maintenance respectively will lead to lower downtime cost and higher reliability of the pusher assembly. Through careful analysis of all the components of the pusher assembly, it was observed that most of the failure that occurs is due to random causes and over stress except all seals and piston rings. Use of precision maintenance requires that all bolts on the assembly should be locked with equal and right torque. In addition, the use of quality bolts and nuts will help reduce failure due to work loosening and bolt breakage (shear) and, thus, will go a long way to save cost due to unproduced products. Avoiding reuse as much as possible but rather using adhesives is recommended. A redesigning of the pusher finger support is suggested on the basis of material selection since its excessive expansion causes the pusher finger bolts to work loose and misalign. A metalogical research should be done to attain a long-lasting material for the pusher that can sustain the working condition better than carbon steel. Experimental research on casehardening by heat treatment could be a solution. The oilers on all pusher assembly must be reinstalled, and frequent cleaning of both the oilers and the cylinder shaft needs to be carried out to avoid accumulation of carbon and dirt which blocks the oilers and makes the cylinder shaft stick. The use of some high technology like acoustic signals, vibration analyser, current signature analysis, and thermal imaging to enhance effective monitoring for early fault diagnosis in the 
pusher cylinder, plunger mechanism, and ware transfer is highly recommended [35-39]. The costs of deploying these monitoring devices will be easily recouped from the significant reduction in downtime that will occur [37].

\subsection{Failure Reporting and Analysis Recommendation}

All recorded downtime on individual sections should not be divided by the total number of sections on the particular machine. Dividing the downtime recorded by the number of sections assumes that the other sections compensate for the failed section by producing more. Since this is not so, the key performance indicator (KPI) for each machine line should be calculated individually. There is the need for a better failure reporting discipline to be implemented in the department. However, this involves input from the workshop floor on failure causes that are not be determined on the machine. This will help in completing the FMEA table more accurately, which will result in carrying out a more detailed failure analysis [40].

Author Contributions: Conceptualization, O.A.; Data curation, E.S.; Formal analysis, S.O.; Investigation, S.O.; Project administration, F.I.; Resources, S.A.A.; Supervision, O.A.; Validation, O.O.; Visualization, F.I.; Writing-original draft, S.O.; Writing—review \& editing, F.I., E.S. and A.A.

Acknowledgments: We are thankful to Covenant University, Ota, Nigeria for publication financial support.

Conflicts of Interest: Authors declare no conflict of interest.

\section{References}

1. Paprocka, I. The model of maintenance planning and production scheduling for maximising robustness. Int. J. Prod. Res. 2018, 1-22. [CrossRef]

2. Zambon, I.; Andrea, P.; Matyjas-łysakowska, P.; Luca, S.; Danilo, M.; Andrea, C. Applied Research for a Safer Future: Exploring Recent Job Accidents in Agriculture, Italy (2012-2017). Processes 2018, 6, 1-13. [CrossRef]

3. Vishnu, C.R.; Regikumar, V. Reliability Based Maintenance Strategy Selection in Process Plants: A Case Study. Procedia Technol. 2016, 25, 1080-1087. [CrossRef]

4. Swanson, L. An empirical study of the relationship between production technology and maintenance management. Int. J. Prod. Econ. 1997, 53, 191-207. [CrossRef]

5. Adoghe, A.U.; Awosope, C.O.A.; Daramola, S.A. Critical Review of Reliability Centred Maintenance (RCM) for Asset Management in Electric Power Distribution System. Int. J. Eng. Technol. 2012, 2, 1020-1026.

6. Muchiri, P.; Pintelon, L.; Gelders, L.; Martin, H. Development of maintenance function performance measurement framework and indicators. Int. J. Prod. Econ. 2011, 131, 295-302. [CrossRef]

7. Suryono, M.; Rosyidi, C.N. Reliability Centred Maintenance (RCM) Analysis of Laser Machine in Filling Lithos at PT X. In Proceedings of the 4th Asia Pacific Conference on Manufacturing Systems and the 3rd International Manufacturing Engineering Conference, Yogyakarta, Indonesia, 7-8 December 2017; IOP Publishing: Bristol, UK, 2018; Volume 319, p. 012020.

8. Abdul-Nour, G.; Beaudoin, H.; Ouellet, P.; Rocheti'e, R.; Lambert, S. A Reliability based Maintenance Policy; A Case of Study. Comput. Ind. Eng. 1998, 35, 591-594. [CrossRef]

9. Deshpande, V.S.; Modak, J.P. Application of RCM for safety considerations in a steel plant. Reliab. Eng. Syst. Saf. 2002, 78, 325-334. [CrossRef]

10. Bolu, C.A. Modeling Maintenance Productivity Measurement of Engineering Production Systems: Discrete Event Simulation Approach. Int. J. Mech. Mechatron. Eng. 2013, 13, 130705-132929.

11. Bozoudis, M.; Lappas, I. Use of Cost-Adjusted Importance Measures for Aircraft System Maintenance Optimization. Aerospace 2018, 5, 1-20. [CrossRef]

12. Rowe, W.H.; Bublitz, A.T. Process Controls for Individual Section Machines. IEEE Trans. Ind. Appl. 1978, I, $153-156$. [CrossRef]

13. Emhart, M.; Jetter, G. Partnering for Perfect Packaging Solutions. 2012. Available online: http://old. emhartglass.com/ files/BR0001RevC.pdf (accessed on 25 October 2018).

14. Ferrari, S. BOTTERO Glass Technologies: Simulation of the B\&B Glass forming Process using VOF. In Proceedings of the STAR Global Conference 2016, Prague, Czech Republic, 7-9 March 2016. 
15. Hiltmann, K.; Neubauer, T. Case study: Gob loading in a glass moulding machine. Procedia CIRP 2016, 39, 203-208.

16. Miller, G.L.; Sullivan, C. Machine-Made Glass Containers and the End of Production for Mouth-Blown Bottles. Hist. Archaeol. 1984, 18, 83-96. [CrossRef]

17. Barbieri, D.; Jacobson, D. Operations and Maintenance in the Glass Container Industry. In Proceedings of the 1999 ACEEE Summer Study on Energy Efficiency in Industry, Albany, NY, USA, 15-18 June 1999; RLW Analytics, Inc.: Troy, NY, USA, 1999; pp. 655-665.

18. Pierpoint, T.J. RCM-The Driver for T\&D condition-based maintenance-A utility perspective. In Proceedings of the 2001 IEEE/PES Transmission and Distribution Conference and Exposition, Atlanta, GA, USA, 2 November 2001; pp. 957-959.

19. Sembiring, N.; Panjaitan, N.; Saragih, F.A. The engine maintenance scheduling by using reliability centered maintenance method and the identification of 5S application in PT. XTZ. In Proceedings of the TALENTA-International Conference on Engineering, Science and Technology 2017 (TALENTA-CEST 2017), Sumatera Utara, Indonesia, 7-8 September 2017; IOP Publishing: Bristol, UK, 2018; Volume 309, p. 012127.

20. Ribeiro, R.T.; Pinto, N.F.A. Reability Centered Maintenance (Rcm), Gain And Results 3 Years After Implementation. In Proceedings of the 2004 International Pipeline Conference, Calgary, AB, Canada, 4-8 October 2004; pp. 1-5.

21. Deshpande, V.S.; Modak, J.P. Application of RCM to a medium scale industry. Reliab. Eng. Syst. Saf. 2002, 77, 31-43. [CrossRef]

22. Mohan, M.; Gandhi, O.P.; Agrawal, V.P. Maintenance strategy for a coal-based steam power plant equipment: A graph theoretic approach. Proc. Inst. Mech. Eng. Part. A J. Power Energy 2004, 218, 619-636. [CrossRef]

23. Cocconcelli, M. Development of a Methodology for Condition-Based Maintenance in a Large-Scale Application Field. Machines 2018, 6, 1-19. [CrossRef]

24. Zhang, T.; Chen, Y.; Wang, C.; Zhang, S. Application of Reliability-centered Maintenance Method in Maintenance and Control Optimization in NPPs. DEStech Trans. Eng. Technol. Res. 2016. [CrossRef]

25. Wang, W.; Majid, H.B. Reliability data analysis and modelling of offshore oil platform plant. J. Qual. Maint. Eng. 2000, 6, 287-295. [CrossRef]

26. Afefy, I.H. Reliability-Centered Maintenance Methodology and Application: A Case Study. Engineering 2010, 2, 863-873. [CrossRef]

27. Ramli, R.; Arffin, M.N. Reliability Centered Maintenance in Schedule Improvement of Automotive Assembly Industry. Am. J. Appl. Sci. 2012, 9, 1232-1236.

28. Tarar, M.A. Study Reliability Centered Maintenance (RCM) of Rotating Equipment through Predictive Maintenance. In Proceedings of the 2nd International Conference on Research in Science, Engineering and Technology (ICRSET'2014), Dubai, UAE, 21-22 March 2014; pp. 2-7.

29. Emovon, I.; Okwu, M. Application of WASPAS In Enhancing Reliability Centered Maintenance for Ship System Maintenance. J. Eng. Technol. 2018, 9, 1.

30. Agarwal, M.; Narayanan, G.A.; Srivastava, P. Risk Prioritization in a Gas Power Plant Using Fuzzy Inference System. In Proceedings of the 8th International Conference on Cloud Computing, Data Science \& Engineering, Nodia, India, 11-12 January 2018; pp. 753-757.

31. Emovon, I.; Mgbemena, C.O. Machinery/service system Scheduled Replacement time determination: A combine Weighted Aggregated Sum Product Assessment, Additive Ratio Assessment and Age Replacement Model approach. Int. J. Integr. Eng. 2018, 10, 169-175. [CrossRef]

32. Tang, Y.; Zhou, D.; Chan, F.T.S. AMWRPN: Ambiguity Measure Weighted Risk Priority Number Model for Failure Mode and Effects Analysis. IEEE Access 2018, 6, 27103-27110. [CrossRef]

33. Emovon, I.; Norman, R.A.; Murphy, A.J. Elements of maintenance systems and tools for implementation within the framework of reliability centred maintenance-A review. J. Mech. Eng. Technol. 2016, 8, 1-34.

34. Sawatdee, T.; Chutima, P.; Device, F.; Zanelli, D. A comparative critical study between FMEA and FTA risk analysis methods. In Proceedings of the CAR2017 International Congress of Automotive and Transport Engineering-Mobility Engineering and Environment, Pitesti, Romania, 8-10 November 2017; IOP Publishing: Bristol, UK, 2017; Volume 252, p. 012046.

35. Glowacz, A. Fault diagnosis of single-phase induction motor based on acoustic signals. Mech. Syst. Signal Process. 2019, 117, 65-80. [CrossRef] 
36. Glowacz, A. Acoustic based fault diagnosis of three-phase induction motor. Appl. Acoust. 2018, 137, 82-89. [CrossRef]

37. Li, H.; Liu, T.; Wu, X.; Chen, Q. Research on bearing fault feature extraction based on singular value decomposition and optimized frequency band entropy. Mech. Syst. Signal Process. 2019, 118, 477-502. [CrossRef]

38. Thomson, W.T. Current Signature Analysis for Condition Monitoring of Cage Induction Motors: Industrial Application And Case Histories; John Wiley \& Sons, Inc.: Hoboken, NJ, USA, 2017; pp. 1-37.

39. Martin, D.K.; VanDyke, J. Integrating Vibration, Motor Current, and Wear Particle Analysis with Machine Operating State for On-line Machinery Prognostics/Diagnostics Systems (MPROS). In Proceedings of the 1997 ASME International Mechanical Engineering Congress and Exposition, New York, NY, USA, 16-21 November 1997; pp. 61-67.

40. Afolalu, A.S.; Salawu, E.Y.; Kehinde, O.; Samuel, U.A.; Ikechi, V.I.; Remilekun, R.E. Failure Mode and Effect Analysis a Tool for Reliability Evaluation. Eur. J. Eng. Res. Sci. 2018, 3, 65-68. [CrossRef]

(C) 2018 by the authors. Licensee MDPI, Basel, Switzerland. This article is an open access article distributed under the terms and conditions of the Creative Commons Attribution (CC BY) license (http:// creativecommons.org/licenses/by/4.0/). 